\title{
In Situ Synchrotron Radiation Measurements During Axial Strain In Hydrogen Cathodically Charged Duplex Stainless Steel SAF 2205
}

\author{
John Jairo Hoyos ${ }^{a, b *}$, Edwar Andrés Torres ${ }^{c}$, Johnnatan Rodríguez Fernández ${ }^{a, d}$, Pedro Craidy ${ }^{e}$,
}

\author{
Marcelo Torres Piza Paes, Antonio José Ramírez ${ }^{a, j}$, André Paulo Tschiptschin ${ }^{a, g}$
}

\author{
${ }^{a}$ Laboratório de Caracterização e Processamento de Metais (CPM), Laboratório Nacional de \\ Nanotecnologia (LNNano), Centro Nacional de Pesquisa de Energia e Materiais (CNPEM), 13083970, \\ Campinas, SP, Brazil \\ ${ }^{b}$ Departamento de Engenharia de Materiais, Universidade Estadual de Ponta Grossa, 84030-900, \\ Ponta Grossa, PR, Brazil \\ 'Universidad de Antioquia, Medellín, Colombia \\ ${ }^{d}$ Escuela de Ingeniería de Antioquia, Universidad EIA, Colombia. \\ ePetrobras, Av. Horácio Macedo, 950, 21941915, Rio de Janeiro, RJ, Brazil \\ ${ }^{f}$ Department of Materials Science and Engineering, Ohio State University, U.S.A. \\ ${ }^{g}$ Departamento de Engenharia Metalúrgica e de Materiais, Escola Politécnica, Universidade de São \\ Paulo, Brazil
}

Received: July 25, 2017; Revised: November 13, 2017; Accepted: November 19, 2017

The objective of this work is the evaluation of hydrogen effects on the martensitic transformation and strain hardening in Duplex Stainless Steels (DSS) SAF 2205 (UNS S32205/S31803). DSS are two-phase alloys (austenite and ferrite), which are used for applications requiring high mechanical strength, in corrosive environments. Therefore, it is necessary a better understanding of the phenomena involved on the hydrogen embrittlement. For this, in situ measurements of X-ray diffraction were made during tensile test in $\mathrm{H}_{2}$ cathodically charging DSS 2205. The hydrogen charging reduces the stress relaxation, reducing the ductility and suppressing the hydrogen-induced austenitic to martensitic transformation. In addition, it also reduces the strain hardening (dislocation multiplication) in austenite. The strain hardening seems to have a higher influence than martensitic transformation on fracture process, even in absence of hydrogen. density

Keywords: Synchrotron radiation, hydrogen embrittlement, strain-induced martensite, dislocation

\section{Introduction}

Duplex Stainless Steels (DSS) are mixtures of ferrite and austenite based on the Fe-Cr-Ni system, with an attractive combination of mechanical properties and corrosion resistance ${ }^{1}$. These steels are used for applications in corrosive environments such as chemical and petrochemical process, chemical tanks, desalination plants, heat exchangers and container pressure tanks ${ }^{2,3}$.

In spite of their outstanding mechanical properties, DSS are susceptible to hydrogen embrittlement ${ }^{4}$. This phenomenon consists on the deterioration on the mechanical properties due to the initiation and growth of cracks by pre-existing defects, decreasing the ductility and promoting the premature failure ${ }^{5}$. Depending on the alloy composition, the plastic deformation can take places more easily in the austenite (DSS with low alloy and N content) or ferrite (highly alloyed DSS), resulting in the initiation and propagation of stress corrosion cracks. After hydrogen-charging in DSS 2205, the ferrite is more sensitivity to cracking than austenite ${ }^{6,7}$.

*e-mail: john.hoyos@lnnano.cnpem.br
The hydrogen enters into the steel through the surface due to localized corrosion or cathodic charging associated with cathodic protection schemes or by galvanic interaction ${ }^{4}$. Then, it diffuses into the steel and its transport occurs mainly through the ferrite since the hydrogen has a higher diffusivity in ferrite than austenite $\left(1 \times 10^{-8} \mathrm{~m}^{2} / \mathrm{s}\right.$ and $1.4-8 \times 10^{-16} \mathrm{~m}^{2} / \mathrm{s}$, respectively) ${ }^{3,8,9}$. However, the diffusion paths in ferrite are not straight because they must pass around the austenite grain. This produces a significant reduction on the diffusivity of hydrogen in comparison to the ferritic steels ${ }^{8}$.

In DSS, hydrogen is trapped in microstructural defects. Depending of the hydrogen-trap binding energy, it is usually classified as diffusible or non-diffusible (residual) ${ }^{9-12}$. This notion is important since only diffusible hydrogen contributes to the hydrogen embrittlement. The diffusible hydrogen is characterized by low activation energy (weak traps). Thus, it takes the form of an interstitial solid solution in ferrite and austenite, and the form of reversible trapped hydrogen at points of structural defects in both phases. These structural defects could be the strain regions around the dislocations, grain boundaries, the dislocations core and vacancies. On 
the other hand, the residual hydrogen is characterized by high activation energy (strong traps). Thus, it takes the form of irreversible trapped hydrogen in structural defects such as high angle boundaries, austenite-ferrite interface and clusters ${ }^{9-12}$.

In addition, hydrogen expands the austenite lattice, promoting the hydrogen-induced phase transformation. This transformation depends on the austenite stability, and mainly consists in the transformation of austenite to austenite hydride or martensite ${ }^{13}$. Besides, hydrogen increases the dislocation density in both ferrite and austenite, and the number of stacking faults in austenite ${ }^{14}$. While the cold work results in an increase in hydrogen uptake, and the subsequent detrimental effect on mechanical properties ${ }^{11}$.

As several mechanisms of hydrogen embrittlement can be overlapped due to the microstructural differences between the ferrite and austenite, the use of in situ experimental techniques could proportionate new elements about the hydrogen effects on the martensitic transformation and dislocation density under load application. For example, in absence of stress (load application), Dabah et al. ${ }^{15}$ showed the influence of hydrogen on the crystal lattices of austenite and martensite $\left(\alpha^{\prime}\right)$ in a super DSS during hydrogen desorption. They point outed the absence of phase transformations.

In this work, correlations between the microstructure, mechanical properties and hydrogen embrittlement in DSS 2205 are established. The strain hardening seems to have a higher influence on hydrogen embrittlement than martensitic transformation. After hydrogen charging, the increase of dislocation density is significantly lower in ferrite than in austenite. This coincides with the brittle cleavage in the ferrite, and the cleavage fracture associated with plastic deformation in the austenite. In absence of hydrogen, the stress relaxation is higher, which could be related to the ductile fracture mode.

\section{Experimental}

The material used in this study was DSS SAF 2205 (Table 1), which was supplied by CPM/LNNano/CNPEM. The as-received steel was in the form of plate, containing austenite and ferrite in a volume ratio of 50:50. Specimens $90 \mathrm{~mm} \times 14 \mathrm{~mm} \times 2 \mathrm{~mm}$ were cut from alloy plate, as it is indicated in the Fig. 1.

Hydrogen was introduced into the previously polished by means of electrochemical cathodic charging at room temperature. The cathodic charging was performed in acid solution containing $0.1 \mathrm{M} \mathrm{H}_{2} \mathrm{SO}_{4}+10 \mathrm{mg} / 1 \mathrm{As}_{2} \mathrm{O}_{3}$ during seven days with a current density of $20 \mathrm{~mA} / \mathrm{cm}^{2}$, using a platinum counter electrode with a diameter of $1 \mathrm{~mm}$. These parameters were chosen in according to the works of Zakroczymski et al. ${ }^{5}$ and Glowacka et al. ${ }^{13}$. Then, the samples were stored under liquid nitrogen bath until the hydrogen content measurements to avoid the hydrogen release. The diffusible and residual hydrogen contents were measured by hot extraction method at $400{ }^{\circ} \mathrm{C}$ and $900{ }^{\circ} \mathrm{C}$ during 40 minutes, respectively. The detection limit of the equipment is $10^{-4} \mathrm{ml} \mathrm{H}_{2} / 100 \mathrm{~g}$, and the precision is $5 \times 10^{-2} \mathrm{ml} \mathrm{H}_{2} / 100 \mathrm{~g}$.

Three samples were analyzed: as-received state (DSS 2205E), cryogenic cooled (DSS 2205C) and hydrogenatedcryogenic cooled (DSS 2205H) specimens. In all samples, synchrotron $\mathrm{X}$-ray measurements were developed with beam energy of $12 \mathrm{keV}\left(\lambda=1.033 \times 10^{-10} \mathrm{~m}\right)$ at room temperature under vacuum $\left(10^{-1} \mathrm{~Pa}\right)$.

The strain were measured using a laser extensometer, and the diffraction data were recorded from $45^{\circ}$ to $66^{\circ}(2 \theta)$ at constant strain in seven points around the center of the gage region, using two solid-state linear detectors, which allow the simultaneous measurement of an angular region of around $20^{\circ}$. These measurements were obtained above $15 \%$ of strain and each $0.5 \%$ of strain over the same $2 \theta$ range. The experiments were performed with a cross head speed of $7.5 \times 10^{-2} \mathrm{~mm} / \mathrm{min}$, resulting in a strain rate of 1.25 $\times 10^{-4} \mathrm{~s}^{-1}$, in the plastic regime prior to necking.

During experiments, the diffraction surface is affected by changes in sample dimensions, which are dependent on temperature and strain. Therefore, it is necessary to calculate the corrected position of the measured diffraction peaks. This correction is made, considering a homogeneous shape change along the sample cross section.

Thus, the diffraction surface will move in a normal direction to the surface plane and the corrected angle position $(\Delta(2 \theta))$ depends on the measured or observed angle $\left(2 \theta_{\text {obs }}\right)$, the sample thickness $(t)$, the angle of incident beam $(\omega)$, the strain of the sample $(\varepsilon)$, and the distance between the detector center and irradiated sample region, which is at the goniometer turning axel (g), as describe in eq. $(1)^{16,17}$. In addition, the peak intensity depends on the diffraction angle since the absorption of the scattered beams is a function of the diffraction angle. Thus, the corrected intensity $(\mathrm{I}(2 \theta))$ depends on the measured intensity $\left(\mathrm{I}_{\mathrm{obs}}(2 \theta)\right)$, the corrected peak angle $(\theta)$ and the incident beam angle $(\omega)$, as describe in eq. (2) ${ }^{16}$.

$$
\begin{gathered}
\Delta(2 \theta)=\tan ^{-1}\left((\varepsilon)\left(\frac{t}{g}\right)\left(\frac{\sin \left(2 \theta_{o b s}\right)}{\sin (\omega)}\right)\right) \\
I(2 \theta) \approx\left(I_{o b s}(2 \theta)\right) e^{-\left(1+\frac{\sin (\omega)}{\sin (2 \theta-\omega)}\right)}
\end{gathered}
$$

Table 1. Chemical composition of the DSS SAF 2205 (UNS S32205/S3180).

\begin{tabular}{lccccccccccccc}
\hline Element (wt. \%) & $\mathrm{C}$ & $\mathrm{Si}$ & $\mathrm{Mn}$ & $\mathrm{Cr}$ & $\mathrm{Ni}$ & $\mathrm{Mo}$ & $\mathrm{N}$ & $\mathrm{P}$ & $\mathrm{S}$ & $\mathrm{Cu}$ & $\begin{array}{c}\text { Other } \\
\text { elements }\end{array}$ & $\mathrm{Fe}$ \\
\hline DSS 2205 & 0.030 & 0.53 & 1.77 & 22.42 & 6.2 & 2.94 & 0.18 & 0.01 & 0.007 & 0.099 & 0.451 & Balance \\
\hline
\end{tabular}


The volume fractions $\left(\mathrm{x}_{\mathrm{i}}\right)$ of the particular phases were estimated from the integrated intensity $\left(\mathrm{I}_{\mathrm{i}}\right)$ and the theoretical intensity ( $\left.\mathrm{R}_{\mathrm{i}}\right)$, as describe in eq. (3) and (4); where $p$ is the plane multiplicity factor, $\mathrm{F}$ is the plane structure factor, and $\mathrm{v}$ is the volume of the unit cell ${ }^{16,17}$.

The temperature factor is not considered because all tests were performed at room temperature with little deformationinduced heating. A Gaussian function was used for X-ray diffraction profile fitting.

$$
\begin{gathered}
x_{i}={\frac{I_{i}^{h k l}}{R_{i}^{h k l}}}_{\sum_{i} \frac{I_{i}^{h k l}}{R_{i}^{h k l}}} \\
R^{h k l}=\frac{p^{h k l}\left|F^{h k l}\right|^{2}\left(e^{\left.-\left(1+\frac{\sin \omega}{\sin (2 \theta-\omega)}\right)\right)}\right.}{\nu_{i}^{2}\left(4 \sin ^{2} \theta \cos \theta\right)}
\end{gathered}
$$

The dislocation density in austenite $\left(\rho_{\gamma}\right)$ and in ferrite $\left(\rho_{\alpha}\right)$ were calculated from the microstrain $(<\mathrm{e}>)$ and the Burger's vector (b), as shown in eq. (5) and (6). The Burger's Vector could be correlated to the lattice parameter (a) for both austenite (face-centered cubic lattice) and ferrite (bodycentered cubic lattice $)^{18}$. The microstrain is estimated by the Stokes and Wilson Method (eq. 7), where $\beta$ is the full width at half maximum (FWHM) corrected by the instrument factor, and $\theta$ is the Bragg angle ${ }^{16,19}$.

$$
\begin{gathered}
\rho_{\gamma}=\frac{3}{\pi}\left(\frac{e}{0.244 b}\right)^{2}=\frac{3}{\pi}\left(\frac{e(2)^{1 / 2}}{0.244(a)}\right)^{2} \\
\rho_{\alpha}=\frac{3}{\pi}\left(\frac{e}{0.244 b}\right)^{2}=\frac{3}{\pi}\left(\frac{2 e}{0.244(3)^{(1 / 2)}(a)}\right)^{2} \\
e=\frac{\beta \cos \theta}{4 \sin \theta}
\end{gathered}
$$

The instrumental broadening was determined using five measurements of high-purity $\mathrm{Y}_{2} \mathrm{O}_{3}$ powder standard. It is important to take in account that the incident beam remains fixed during tensile tests. Therefore, only the (220) $\gamma,(311) \gamma$, (222) $\gamma,(211) \alpha^{\prime}$ and (220) $\alpha^{\prime}$ diffraction peaks are considered for the estimation of volume fractions and dislocation density as a function of strain. In absence of stress, all diffraction peaks are considered.

\section{Results and Discussion}

Table 2 shows the measurements of hydrogen at 400 ${ }^{\circ} \mathrm{C}$ and $900{ }^{\circ} \mathrm{C}$ during 40 minutes, in the as-received and hydrogenated specimens. The cathodic charging increased mostly the hydrogen measurement at $400{ }^{\circ} \mathrm{C}$, which is

\begin{tabular}{|c|c|c|c|c|}
\hline \multirow{2}{*}{ Sample } & \multirow{2}{*}{ Description } & \multicolumn{2}{|c|}{$\begin{array}{l}\text { Measurement } \\
\text { conditions }\end{array}$} & \multirow{2}{*}{$\begin{array}{c}\text { Hydrogen } \\
\text { (ml } \\
\mathrm{H}_{2} / 100 \\
\mathrm{~g}) /(\mathrm{ppm})\end{array}$} \\
\hline & & $\begin{array}{c}\text { Temperature } \\
\left({ }^{\circ} \mathrm{C}\right)\end{array}$ & $\begin{array}{l}\text { Time } \\
\text { (min) }\end{array}$ & \\
\hline \multirow{2}{*}{$\begin{array}{l}\text { DSS } \\
2205 \mathrm{E}\end{array}$} & \multirow{2}{*}{$\begin{array}{l}\text { As-received } \\
\text { (non- } \\
\text { hydrogenated) }\end{array}$} & 400 & 40 & $\begin{array}{c}0.11 / \\
(0.09)\end{array}$ \\
\hline & & 900 & 40 & $\begin{array}{c}0.12 / \\
(0.10)\end{array}$ \\
\hline \multirow{2}{*}{$\begin{array}{l}\text { DSS } \\
2205 \mathrm{H}\end{array}$} & \multirow{2}{*}{ Hydrogenated } & 400 & 40 & $\begin{array}{c}5.57 / \\
(4.67)\end{array}$ \\
\hline & & 900 & 40 & $\begin{array}{l}0.53 / \\
(0.44)\end{array}$ \\
\hline
\end{tabular}

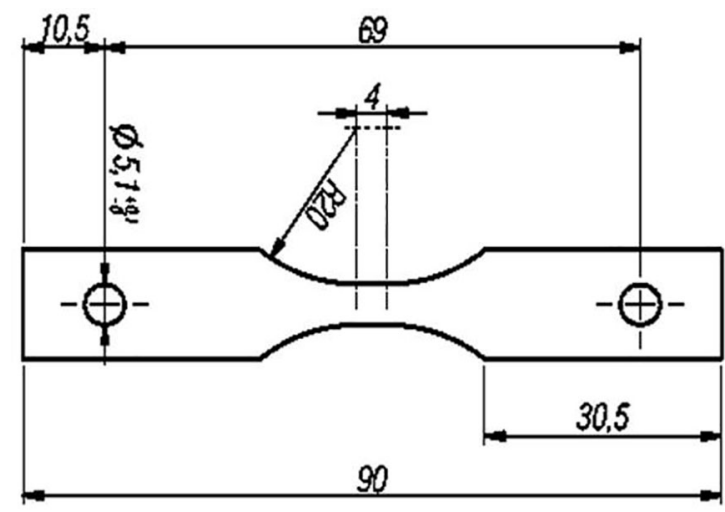

Figure 1. Schematic view of the tensile test samples; measurements in $\mathrm{mm}$.

Table 2. Measurements of diffusible and residual hydrogen.

Table 3. Mechanical properties of hydrogenated and non-hydrogenated samples.

\begin{tabular}{lcccc}
\hline Sample & $\begin{array}{c}0.2 \text { yield } \\
\text { strength } \\
(\mathrm{MPa})\end{array}$ & $\begin{array}{c}\text { Ultimate } \\
\text { tensile } \\
\text { strength } \\
(\mathrm{MPa})\end{array}$ & $\begin{array}{c}\text { Elongation } \\
\text { at fracture } \\
(\%)\end{array}$ & $\begin{array}{c}\text { Reduction } \\
\text { of area } \\
(\%)\end{array}$ \\
\hline DSS 2205E & 533 & 771 & 27 & 91 \\
DSS 2205C & 548 & 768 & 33 & 90 \\
DSS 2205H & 576 & 800 & 20 & 25 \\
\hline
\end{tabular}

considered as diffusible hydrogen since it has lower activation energy (weak traps) $)^{9-12}$. On the other hand, the increase of hydrogen measured at $900{ }^{\circ} \mathrm{C}$ cannot be deemed significant. This hydrogen is considered as non-diffusible hydrogen (residual) since it has high activation energy (strong traps). This suggests that the hydrogen transport is mainly in lattice diffusion and hydrogen traps of low energy, which is in according with the results obtained by Luu et al. ${ }^{20}$. In addition, more hydrogen should be in ferrite since the hydrogen diffusivity and permeation rate is higher in ferrite than austenite ${ }^{21,22}$. The residual hydrogen could be associated to the hydrogen trapped inside traps of higher activation energy such as interface $\gamma-\alpha$ and clusters ${ }^{11,12}$. 


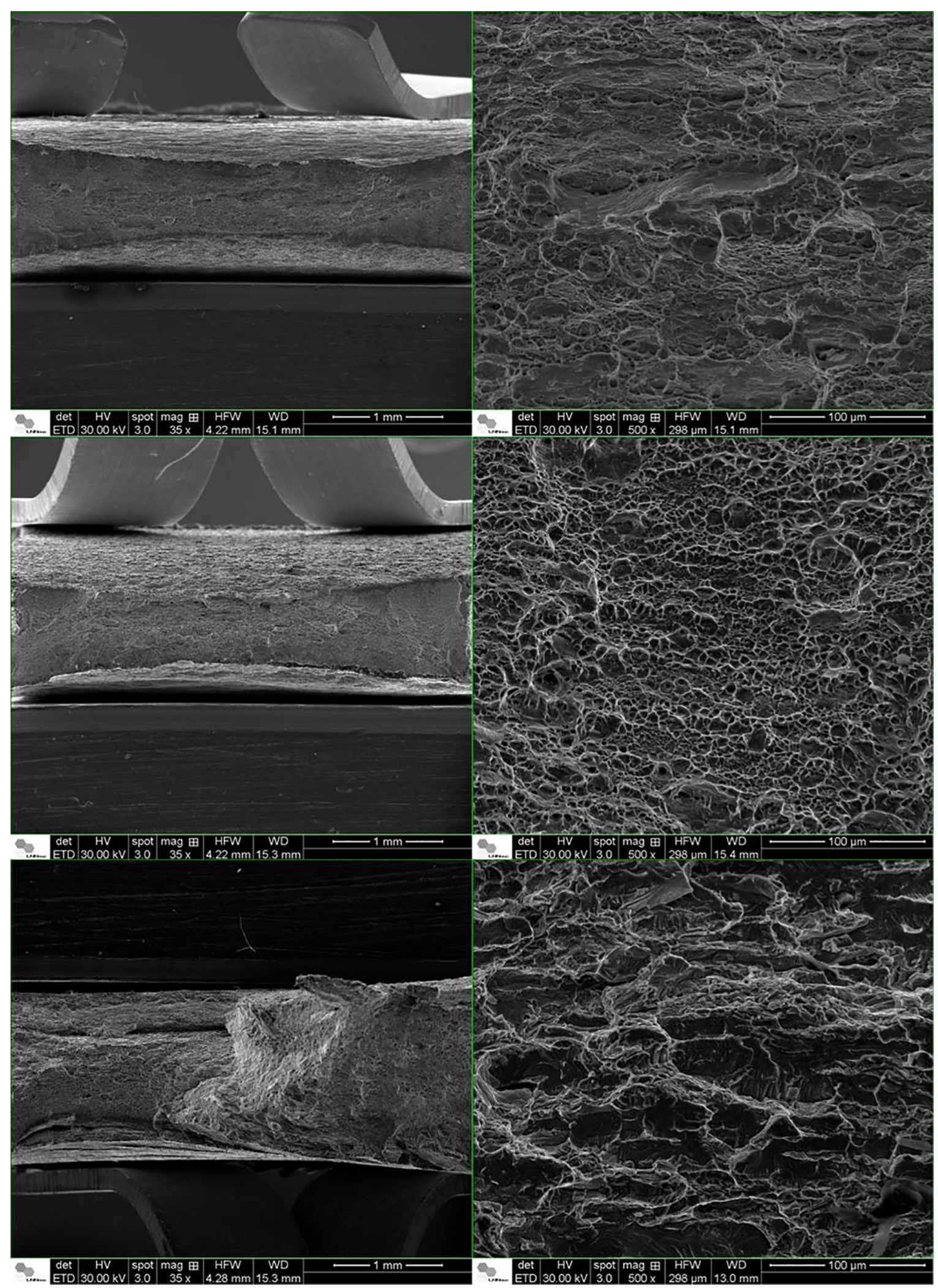

Figure 2. Fracture surfaces of the as-received specimen (top), the cryogenic cooled specimen (middle) and the hydrogenated specimen (bottom). 

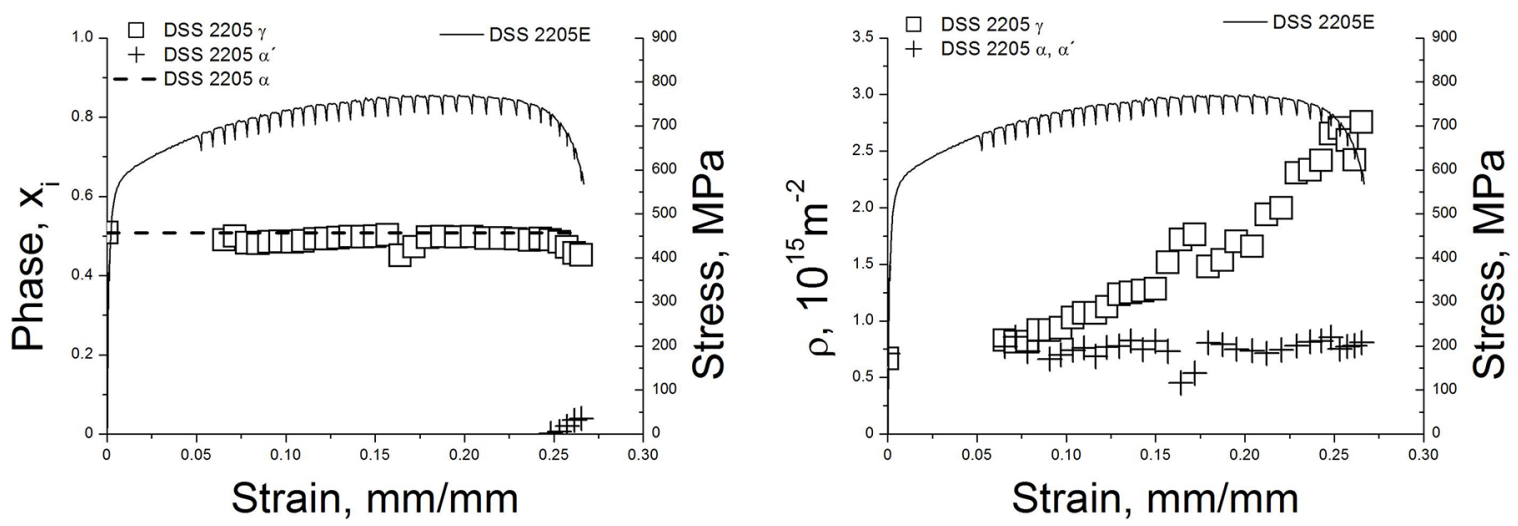

Figure 3. a) Volume fraction of the phases (left) and dislocation density (right) for the as-received specimen.

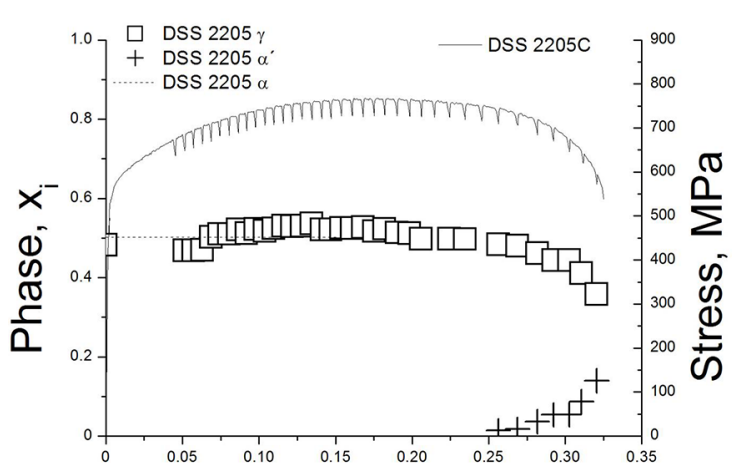

Strain, $\mathrm{mm} / \mathrm{mm}$

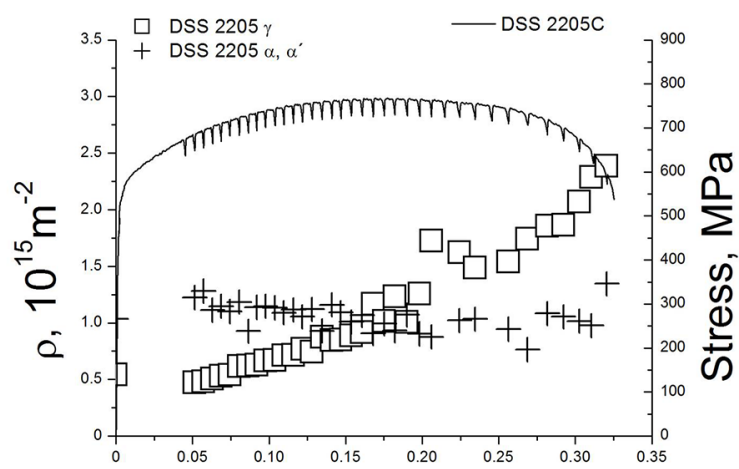

Strain, $\mathrm{mm} / \mathrm{mm}$

Figure 4. a) Volume fraction of the phases (left) and dislocation density (right) for the cryogenic cooled specimen.
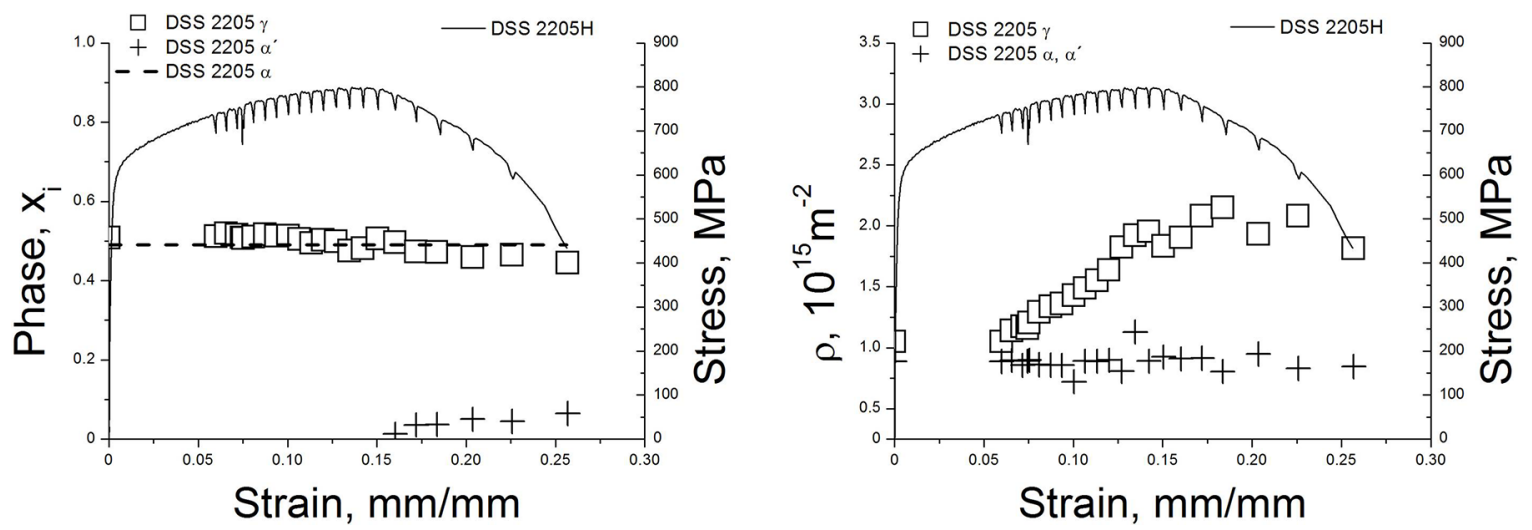

Figure 5. a) Volume fraction of the phases (left) and dislocation density (right) for the hydrogenated specimen.

As the hydrogen charging was made in absence of load application, the hydrogen concentration is lower than that obtained by Luu et al. ${ }^{20}$ and Zakcrocczymski et al. ${ }^{21}$. However, this concentration is higher than the threshold total hydrogen concentration (1-5 ppm) which can cause a ductility loss in these steels. According with Zakcrocczymski et al..$^{21}$ the presence only of hydrogen as an interstitial solid solution can decrease the ductility during axial strain.

As it is indicated in table 3, the cryogenic cooled increased slightly the elongation at fracture whereas the hydrogen-charging induced a significant loss in ductility.
The hydrogenated specimen had lower reduction of area and elongation at fracture. This was related to the higher hydrogen content. This decrease of ductility is similar to

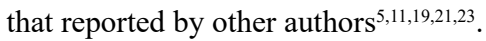

The difference in the steel ductility can be observed in fracture surfaces (Fig. 2). In the as-received and cryogenic cooled specimens, the fracture mode was mainly ductile. Thus, microvoids and an extensive plastic deformation (necking) can be observed. Whereas in the hydrogenated specimen, there is not apparent necking and some cracks were observed. This suggests that crack propagation is along 
cleavage planes. The hydrogen promoted a brittle cleavage in the ferrite phase, and a cleavage fracture associated with plastic deformation (rough stepwise cracking) in the austenitic phase $\mathrm{e}^{11,19,20}$. This behavior is similar to the observed by other authors, which pointed out the origin of the crack in the ferrite ${ }^{11,19,20}$.

The formation of strain-induced martensite for the asreceived specimen is observed in the Fig. 3, which shows the kinetics of the martensitic transformation and dislocation density as a function of strain. The dislocation density in austenite increased from the onset of necking, whereas the increase in the dislocation density in ferrite was not significantly. On the other hand, the austenite transformed to $\alpha^{\prime}$ martensite only after high plastic deformation (end of necking), indicating that it was a consequence of the strain and not the cause of the necking.

This behavior is similar to the observed in Fig. 4 for the cryogenic cooled sample, suggesting that the strain hardening in both specimens have a higher influence than martensitic transformation on fracture process.

Fig. 5 shows the behavior of the martensitic transformation and of dislocation density in the hydrogenated specimen. The behavior of the dislocation density in both ferrite and austenite was similar to those observed in the other specimens.

Furthermore, the hydrogen did not seem to increase the dislocation density in both ferrite and austenite, and hydrogeninduced martensite formation is not observed. Although strain-induced austenitic to martensitic transformation appeared at lower strain, the final volume of martensite and the dislocation density in austenite are lower than those reached in absence of hydrogen. According with Luu et al. ${ }^{20}$, in this steel the austenite is less sensitivity in hydrogen embrittlement and causes less deformation, which inhibits the martensitic transformation.

It is usually considered that the ferrite is more sensitivity to cracking than austenite under hydrogen effects ${ }^{5-7}$. This coincides with the lower strain hardening in the ferrite since the higher dislocation density in the austenite indicates a higher stress relaxation. Furthermore, the evolution of the dislocation density in both phases coincides with the brittle cleavage in the ferrite, and the cleavage fracture associated with plastic deformation in the austenite for the hydrogenated specimen.

Therefore, the hydrogen embrittlement could be related to the decrease on the stress relaxation in both ferrite and austenite phases. In the austenite, this causes less plastic deformation, and thus inhibits the subsequent stress relaxation by strain hardening and the martensitic transformation. In absence of hydrogen, the ductile fracture mode could be related to the higher stress relaxation, which is manifested mainly by high plastic deformation in austenite.

It is important to take in account, the decrease of the martensite formation for the hydrogenated specimen. In first place, it is not observed hydrogen-induced martensite due to the hydrogen charging. This could be related to the low residual hydrogen since the hydrogen transport is mainly in lattice diffusion (low energy traps). According with Glowacka et al. ${ }^{13,14}$, the hydrogen charging can induce the formation of martensite $\varepsilon$ or $\alpha^{\prime}$. Nevertheless, Silverstein et al. ${ }^{24}$ pointed out that the hydrogen traps of higher energy (residual hydrogen) such as high angle boundaries, vacancy, austenite-ferrite interface and clusters are related to the transformation from austenite to martensite during hydrogen charging; while the hydrogen traps of low energy such (diffusible hydrogen) such as elastic stress field of dislocations, screw's dislocation core or grain boundaries do not have a significant influence in the hydrogen-induced phase transformations. In second place, hydrogen decreased the martensite formation during axial strain. This suggests a lower stress relaxation since hydrogen-induced phase transformation is a main mechanism for stress relaxation ${ }^{25}$, and it is in according with the decrease of the steel ductility.

\section{Conclusions}

The hydrogen-charging increases mainly the diffusible hydrogen (low energy traps), inducing the deterioration in mechanical properties. This could be related to the hydrogen effects on strain hardening (dislocation multiplication) and martensitic transformation. Under hydrogen effects the strain-induced martensite formation and the dislocation density in austenite seem to reach lower values than those obtained in absence of hydrogen, inducing the fracture transition mode from ductile to brittle. In addition, the evolution of the dislocation density in both phases under hydrogen effects coincides with the mixture of typical facet cleavage fracture in ferrite and cleavage fracture associated with plastic deformation in the austenite. In absence of hydrogen, the stress relaxation is higher, promoting a ductile fracture mode.

\section{Acknowledgements}

This work was supported by CNPq (Project 403530/20148 ). The authors are grateful to the LNNano/CNPEM for the technical support during the usage of the XTMS installation and LNLS/CNPEM for the infrastructure present in the XRD1 beamline (Proposal 20160465). The authors are also grateful to Mr. Leonardo Wu for help during the synchrotron radiation experiments.

\section{References}

1. Baddoo NR. Stainless steel in construction: A review of research, applications, challenges and opportunities. Journal of Constructional Steel Research. 2008;64(11):1199-1206.

2. Olsson J, Snis M. Duplex - A new generation of stainless steels for desalination plants. Desalination. 2007;205(1-3):104-113. 
3. Dabah E, Lisitsyn V, Eliezer D. Performance of hydrogen trapping and phase transformation in hydrogenated duplex stainless steels. Materials Science and Engineering: A. 2010;527(1819):4851-4857.

4. Lo KH, Shek CH, Lai JKL. Recent developments in stainless steels. Materials Science and Engineering: R: Reports. 2009;65(4-6):39-104.

5. Zakroczymski T, Glowacka A, Swiatnicki W. Effect of hydrogen concentration on the embrittlement of a duplex stainless steel. Corrosion Science. 2005;47(6):1403-1414.

6. Young MC, Chan SLI, Tsay LW, Shin CS. Hydrogen-enhanced cracking of 2205 duplex stainless steel welds. Materials Chemistry and Physics. 2005;91(1):21-27.

7. Chou SL, Tsai WT. Effect of grain size on the hydrogen-assisted cracking in duplex stainless steels. Materials Science and Engineering: A. 1999;270(2):219-224.

8. da Silva BRS, Salvio F, dos Santos DS. Hydrogen induced stress cracking in UNS S32750 super duplex stainless steel tube weld joint. International Journal of Hydrogen Energy. 2015;40(47):17091-17101.

9. Owczarek E, Zakrocymski T. Hydrogen transport in a duplex stainless steel. Acta Materialia. 2000;48(12):3059-3070.

10. Silverstein R, Eliezer D, Glam B. Hydrogen Effect on Duplex Stainless Steels at Very High Strain Rates. Energy Procedia. 2017;107:199-204.

11. Elhoud AM, Renton NC, Deans WF. Hydrogen embrittlement of super duplex stainless steel in acid solution. International Journal of Hydrogen Energy. 2010;35(12):6455-6464.

12. Silverstein R, Eliezer D, Glam B, Eliezer S, Moreno D. Evaluation of hydrogen trapping mechanisms during performance of different hydrogen fugacity in a lean duplex stainless steel. Journal of Alloys and Compounds. 2015;648:601-608.

13. Glowacka A, Wozniak MJ, Świa tnicki WA. AFM study of austeno-ferritic stainless steel microstructure after cathodic hydrogen charging. Journal of Alloys and Compounds. 2005;404406:595-598.
14. Glowacka A, Świa tnicki WA. Effect of hydrogen charging on the microstructure of duplex stainless steel. Journal of Alloys and Compounds. 2003;356-357:701-704.

15. Dabah E, Kannengiesser T, Eliezer D, Boellinghaus T. In situ analysis of hydrogen behaviour in stainless steels by high energy synchrotron radiation. Materials Science and Engineering: $A$. 2011;528(3):1608-1614.

16. Cullity BD, Stock SR. Elements of X-Ray Diffraction. New York: Prentice Hall; 2001.

17. Faria G. Exploring metallic materials behavior through in situ crystallographic studies by synchrotron radiation. [Thesis]. Campinas: Department of Mechanical Engineering, University of Campinas; 2014.

18. Michler T, Naumann J, Hock M, Berreth K, Balogh MP, Sattler E. Microstructural properties controlling hydrogen environment embrittlement of cold worked 316 type austenitic stainless steels. Materials Science and Engineering: A. 2015;628:252-261.

19. Williamson GK, Hall WH. X-ray line broadening from filed aluminium and wolfram. Acta Metallurgica. 1953;1(1):22-31.

20. Luu WC, Liu PW, Wu JK. Hydrogen transport and degradation of a commercial duplex stainless steel. Corrosion Science. 2002;44(8):1783-1791.

21. Zakroczymski T, Owczarek E. Electrochemical investigation of hydrogen absorption in a duplex stainless steel. Acta Materialia. 2002;50(10):2701-2713.

22. Vánová P, Sojka J. Hydrogen embrittlement of duplex steel tested using slow strain rate test. Metalurgija. 2014:53(2):163166.

23. Chen SS, Wu TI, Wu JK. Effects of deformation on hydrogen degradation in a duplex stainless steel. Journal of Materials Science. 2004;39(1):67-71.

24. Silverstein R, Sobol O, Boellinghaus T, Unger W, Eliezer D. Hydrogen behavior in SAF 2205 duplex stainless steel. Journal of Alloys and Compounds. 2017;695:2689-2695.

25. Rozenak P, Zevin L, Eliezer D. Hydrogen effects on phase transformations in austenitic stainless steels. Journal of Materials Science. 1984;19(2):567-573. 